\title{
Should a statin be routinely prescribed for primary prevention of cardiovascular disease in diabetes mellitus?
}

Colhoun HM, Betteridge DJ, Durrington PN, Hitman GA, Neil HAW, Livingstone SJ, et al; CARDS investigators. Primary prevention of cardiovascular disease with atorvastatin in type 2 diabetes in the Collaborative Atorvastatin Diabetes Study (CARDS): multicentre randomised placebo-controlled trial. Lancet 2004;364:685-96.

Background: HMG-CoA reductase inhibitors (statins) are effective in reducing the risk of cardiovascular events in patients with cardiovascular disease (CVD) or hypercholesterolemia. However, their effectiveness in the primary prevention of CVD in patients with type 2 diabetes and no history of atherosclerosis is less clear.

Design: This double-blind study enrolled 2838 patients aged 4075 with type 2 diabetes who had no known CVD but at least 1 additional cardiovascular risk factor (hypertension, retinopathy, albuminuria or current smoking). Patients were randomly allocated to receive placebo or $10 \mathrm{mg}$ of atorvastatin daily. The primary outcome measure was the composite of acute coronary syndrome, coronary revascularization or stroke. All analyses were by intentionto-treat. The trial was ended 2 years early because of significant evidence of efficacy.

Results: The average participant was male $(68 \%)$, was 62 years old, had medication-treated diabetes known for an average of 8 years, was overweight (mean body mass index 29) and had hypertension (84\%). Control of blood glucose and glycated hemoglobin was poor, and only 1 in 7 patients was taking ASA or another antiplatelet drug at baseline; less than half received an angiotensin-converting-enzyme inhibitor. Study outcomes are summarized in Table 1. Treatment was safe and well tolerated.

Commentary: At first glance, the data appear to support the authors' conclusion that most, if not all, patients with type 2 diabetes should be considered for long-term statin therapy. Indeed, the researchers went a long way toward proving their hypothesis: they excluded patients with known CVD (in whom benefit was already demonstrated); they used a low dose of a potent statin to maximize efficacy and minimize toxicity; and they enrolled many patients whose cholesterol levels were below current recommended treatment thresholds. However, the average participant had long-standing diabetes with multiple additional risk factors that were substantially undertreated. Thus, it remains to be seen whether the benefits would be realized in diabetic patients who did not have similar risk factors or who were optimally treated for their comorbidities. Also, the study excluded patients at extremes of age $(<40$ and $>$ 75 ), those with evidence of cardiac, renal or hepatic insufficiency, marked obesity (body mass index > 35), severely uncontrolled diabetes, suboptimal compliance, and those with any of a range of laboratory abnormalities. Thus, despite the authors' assertions, the generalizability of these results to all diabetic patients has not been established. Moreover, although the positive results of CARDS are congruent with those from a previous study, ${ }^{1}$ they differ from the findings among diabetic patients in 2 other major studies. ${ }^{2,3}$

Practice implications: Patients with diabetes are a heterogenous group with varying risks of cardiovascular events. Those with
CVD should receive a statin regardless of their low-density lipoprotein cholesterol level, because of their extremely high risk for future events. For those without CVD, the clinician must still carefully consider the patient's baseline risk and personal preferences, as well as the expense and inconvenience of long-term treatment.

\section{Daniel G. Hackam}

Division of Clinical Pharmacology Sunnybrook and Women's College Health Sciences Centre

Toronto, Ont.

\section{References \\ 1. Collins R, Armitage J, Parish S, Sleigh P, Peto R. MRC/BHF Heart Protection Study of cholesterol- lowering with simvastatin in 5963 people with diabetes: a randomised placebo-controlled trial. Lancet 2003; 361:2005-16. \\ 2. Sever PS, Dahlof B, Poulter NR, Wedel H, Beevers G, Caulfield M, et al. Prevention of coronary and stroke events with atorvastatin in hyperten- sive patients who have average or lower-than-average cholesterol con- centrations, in the Anglo-Scandina- vian Cardiac Outcomes Trial-Lipid Lowering Arm (ASCOT-LLA): a multicentre randomised controlled trial. Lancet 2003;361:1149-58. \\ 3. ALLHAT Officers and Coordinators for the ALLHAT Collaborative Re- search Group. Major outcomes in moderately hypercholesterolemic, hy- pertensive patients randomized to pravastatin vs usual care: the Antihy- pertensive and Lipid-Lowering Treatment to Prevent Heart Attack Trial (ALLHAT-LLT). 7AMA 2002; 288:2998-3007.}

Table 1: Effect of atorvastatin on study end points*

\begin{tabular}{|c|c|c|c|}
\hline \multirow[b]{2}{*}{ End point } & \multicolumn{2}{|c|}{ Group; no. (\%) of patients } & \multirow{2}{*}{$\begin{array}{c}\text { Hazard ratio } \\
(95 \% \mathrm{Cl})\end{array}$} \\
\hline & Placebo & Atorvastatin & \\
\hline Primary (composite) & $127 \quad(9.0)$ & $83(5.8)$ & $0.63(0.48-0.83)$ \\
\hline Acute coronary events & $77 \quad(5.5)$ & $51(3.6)$ & $0.64(0.45-0.91)$ \\
\hline $\begin{array}{l}\text { Coronary } \\
\text { revascularization }\end{array}$ & $34 \quad(2.4)$ & $24(1.7)$ & $0.69(0.41-1.16)$ \\
\hline $\begin{array}{l}\text { Stroke } \\
\text { Secondary }\end{array}$ & $39 \quad(2.8)$ & $21(1.5)$ & $0.52(0.31-0.89)$ \\
\hline $\begin{array}{l}\text { Death from any cause } \\
\text { Any acute cardiovascular } \\
\text { event }\end{array}$ & $82 \quad(5.8)$ & $61(4.3)$ & $0.73(0.52-1.01)$ \\
\hline
\end{tabular}

Note: $\mathrm{Cl}=$ confidence interval

*Median follow-up was 4 years. 